\title{
Promotion by Pharmaceutical Industry and Patients' Perspective in Pakistan
}

\author{
Dr. Sadaf Mustafa \\ Assistant Professor at Department of Commerce, \\ University of Karachi \\ Ahmed Osama \\ Research Scholar, Department of Commerce, \\ University of Karachi, Pakistan \\ Reema Akber \\ Research Scholar, Department Of Economics, \\ University Of Karachi, Pakistan \\ Samana Johari \\ Research Scholar, Department of Commerce, \\ University of Karachi, Pakistan
}

Doi: 10.19044/esj.2018.v14n21p119 URL:http://dx.doi.org/10.19044/esj.2018.v14n21p119

\begin{abstract}
The economy of Pakistan is significantly contributed by the pharmaceutical industry which is growing at a rapid rate. For pharmaceutical industry doctor is one of the most important stakeholders because he is the ultimate decision maker rather than the direct user. Pharmaceutical industry focuses on doctors rather than the direct users; BTL i.e. below the line marketing strategy is the basis of marketing in pharmaceutical industry, the importance of sales promotion officers as a marketing technique in pharmaceutical industry cannot be denied and ignored. In order to reach the doctors i.e. the prescribers, pharmaceutical industry takes the help of sales promotion officers that constitutes a major place in pharmaceutical marketing strategies. The connection of pharmaceutical industry with physicians is controversial due to the involvement of personal benefits and clash between money and ethics. Trust is one of the fundamental factors of patient-physician relationships, despite of its recognized significance and efforts to measure patient trust have been quite insufficient. This study investigates the patients' perspective regarding the sales promotion by pharmaceutical industry, it highlights the viewpoint of one of the most important stakeholders of health care industry i.e. the patients regarding the matter. Questionnaire was used as the research tool to collect the primary data from patients, 100 questionnaires were filled up from a hospital of Karachi.
\end{abstract}


Keywords: Pharmaceutical industry, Doctor, Stakeholder, Decision maker, Patients, Promotion, BTL, Sales promotion officers, Money, Ethics.

\section{Introduction}

\section{Global Pharmaceutical Market:}

The value of pharmaceutical market of the entire world is around 650 billion US\$ (2008-2009) with 8\% annual growth rate and it is expected that its value will be around 1.1 trillion US\$ up to 2015 , if the same rate is continued in terms of value, Japan, EU and USA are ruling the global market with $12 \%$, $28 \%$ and $48 \%$ market shares respectively (Mehmood, 2016).

\section{Pakistan Pharmaceutical Market:}

Physicians and pharmaceutical industry are considered as the major players of healthcare industry (Amin, 2012). The economy of Pakistan is significantly contributed by the pharmaceutical industry which is growing at a rapid rate (Zaman, 2011). In Pakistan there are about 750 registered pharmaceutical manufacturing units out of which 400 are actively producing finished drugs, including those operated by 24 multinationals. The ratio of multinational and national companies in pharmaceutical industry of Pakistan is 2:3; GSK is at the top among multinationals while Getz Pharmaceutical among nationals with the market shares of $11.60 \%$ and $3.75 \%$ respectively. (Mehmood, 2016). Around $80 \%$ of the local market demand is fulfilled by the pharmaceutical industry of Pakistan, $90 \%$ of active ingredients used in the making of medicines are imported (Rizwan Raheem Ahmed, 2014).

\section{New Tends in Marketing of Pharmaceutical Products:}

BTL i.e. below the line marketing strategy is the basis of marketing in pharmaceutical industry. Pharmaceutical industry focus on doctors rather than the direct users. Periodic visits of sales promotion officers, drug samples, direct mail, promotional products, promotional fax, events and medical journal product information are the various promotional tools/ techniques used in pharmaceutical industry(Aisha Muhammad Arif, 2015).In order to reach the doctors i.e. the prescribers, pharmaceutical industry takes the help of sales promotion officers that constitutes a major place in pharmaceutical marketing strategies. Though the importance of sales promotion officers cannot be denied and ignored but this promotional technique is quite costly for the pharmaceutical companies. The use of internet for promotion in addition to the sales promotion officers is the need of today, this combination is helping out the pharmaceutical companies to reduce their fixed cost which occurs in terms of compensation to salespromotion officers. Internet or social media 
marketing is the need of marketing in all the industries(Rizwan Raheem Ahmed, 2014).

\section{Connection of Pharmaceutical Industry with Physicians:}

The marketing of pharmaceutical products is the part of everyday life of physicians (Allan S. Brett, Wayne Burr, \& Jamaluddin Moloo, 2003).For pharmaceutical industry doctor is one of the most important stakeholders because he is the ultimate decision maker rather than the direct user. The connection of pharmaceutical industry with physicians is controversial due to the involvement of personal benefits and clash between money and ethics. According to a number of researchers, good relationship of medical representatives with physicians has a great impact over the prescription behavior (Rizwan Raheem Ahmed, 2014).

This study investigates the patients' perspective regarding the sales promotion by pharmaceutical industry. It highlights the viewpoint of one of the most important stakeholders of health care industry i.e. the patients regarding the matter.

\section{Literature Review:}

\section{Pharmaceutical Industry Gifts:}

Pharmaceutical industry gifts which are given to the physicians are very important promotional technique used by different companies of the industry. The gifts given to physicians include, but not limited to note pads, pen lights, ballpoint pens, lunches and dinners and lavish expense paid trips to medical conferences at appealing vocation resorts. These gifts are considered as the controversial strategy used by pharmaceutical companies in order to promote their brands (Robert L. Blake, 1995). Though the professional guidelines for the activity are available, but despite of the fact concerns exist regarding the ethical implications of pharmaceutical industry gifts. According to ACP (American College of Physicians) the knowledge of others perspectives about the pharmaceutical industry gifts is needed (Robert V. Gibbons, 1998).A study from the University of Toronto reveals that in a period of about year, psychiatry residents and internsattended around 35 meetings and 70 lunches and received around 75 promotional items. Promotion and marketing constitutes a great portion of the activities done by pharmaceutical companies and its importance cannot be denied and ignored(Kerridge, 2002). Gifts given to physicians by pharmaceutical companies is beneficial for both the parties, but it cannot be considered as something beneficial for the patients because it increases the health care expenses(Jason Dana \& George Loewenstein, 2003).Medical practitioners today spend their time in listening the medical representatives and receiving gifts from them, if it is asked that why they do this, majority of them would be shocked(Howard Brody, 2005). 
Variety of researches reveal the fact that almost every physician accepts gifts given by pharmaceutical industry(Kenneth V. Iserson, 2007).

\section{Patients' Health vs. Financial Gain:}

Pharmaceutical companies, hospitals, clinics and health workers all are the part of health care industry. Like other industries, it is also quite common for the companies in health care industry to have financial goals and objectives, the concern however arises when the patients' health is compromised for the sake of financial gain, this compromise opens the doors for researchers to conduct studies in order to explore various dimensions like interaction between sales representatives and medical practitioners (Rhee, 2008), this collision between patients' health and financial gain is not confined to Pakistan, it has a huge impact over physicians' prescription behavior worldwide (Hsiao, 2008).

Pharmaceutical industry interaction with physicians may undermine the patients' welfare and increase the cost of healthcare which is a matter of great concern (Macneill P, 2010).Unethical promotion of pharmaceutical products is not confined to the developing countries, it is a worldwide phenomenon, however, it is quite severe in developing countries like Pakistan(Ahmed, 2012).

\section{Doctors as Decision Makers:}

Marketing in pharmaceutical industry is quite different from other industries, e.g. FMCG industry, because in pharmaceutical industry the target audience is not the patients but the doctor who makes the decision on behalf of their patients, this difference make the marketing in pharmaceutical industry quite unique. Physicians have the right to recognize the need of the patients and recommend the medicines for the betterment of their patients. The relationship of pharmaceutical companies with physicians may result in conflict between ethics and self-interest, most of the times the relation is not illegal even in developing countries but ethical concerns arise due to the interaction of pharmaceutical companies with physicians. Pharmaceutical companies spend large amounts of money on promotion of their brands and the promotional expenditures are recovered through prices of the medicines, hence it increases the cost of health care (Narendranathan, 2013).

\section{Importance of Trust:}

Trust is one of the fundamental factors of patient-physician relationships, relation between doctor and patient is supposed to be strong and trust worthy otherwise the negative psychological effect would not let the patient recover from illness, hence the importance of trust in doctor patient relationship cannot be denied and ignored and for trust building, medical 
ethics is vital, despite of its recognized significance and efforts to measure patient trust have been quite insufficient. However, the conflict of interestbetween money and ethics may impact the relationship of doctor and patient (Avinash R. Patwardhan, 2016). Legality is equally demanded by all the professions of this world, every professional is supposed to behave legally in all the aspects of profession, although the level of ethics demanded by different professions is different, there are certain professions in this world which demand the highest levels of ethical behavior, the profession of a doctor is one of them. The result of interaction between physicians and medical representatives is a conflict of interest and physicians may get failed to stand with their moral and legal responsibilities for financial gain(Shahzad Salmasi, 2016).

\section{Sampling And Methodology:}

Questionnaire was used as the research tool to collect the primary data from patients, 100 questionnaires were filled up from a hospital of Karachi, in order to investigate the patients' perspective regarding different sales promotion techniques used by pharmaceutical companies to promote their brands.

\section{Limitations Of The Study:}

Convenience sampling method was adopted in order to collect the primary data from patients and therefore there are the chances of error. Limited number of respondents is also the limitation of this study.

\section{Data Analysis:}

\begin{tabular}{|c|c|c|c|}
\hline $\begin{array}{c}\text { Impact of gifts on patients' trust in } \\
\text { doctors }\end{array}$ & Code $(\mathrm{x})$ & $\mathrm{f}$ & $\mathrm{fx}$ \\
\hline Very Good & -2 & 2 & -4 \\
\hline Good & -1 & 13 & -13 \\
\hline Average & 0 & 6 & 0 \\
\hline Bad & 1 & 42 & 42 \\
\hline Very Bad & 2 & 37 & 74 \\
\hline Total & & 100 & 99 \\
\hline
\end{tabular}

Mean $=1.01$

Mean value is 1.01 which reveals that gifts as a sales promotion technique have a negative impact on patients' trust in doctors. 


\begin{tabular}{|c|c|c|c|}
\hline $\begin{array}{c}\text { Impact of gifts on patients' trust in } \\
\text { pharmaceutical companies }\end{array}$ & Code $(\mathrm{x})$ & $\mathrm{f}$ & $\mathrm{fx}$ \\
\hline Very Good & -2 & 11 & -22 \\
\hline Good & -1 & 6 & -6 \\
\hline Average & 0 & 8 & 0 \\
\hline Bad & 1 & 31 & 31 \\
\hline Very Bad & 2 & 44 & 88 \\
\hline Total & & 100 & 91 \\
\hline
\end{tabular}

Mean $=0.91$

Mean value is 0.91 which shows that gifts as a sales promotion technique have a negative impact on patients' trust in pharmaceutical companies.

\begin{tabular}{|c|c|c|c|}
\hline $\begin{array}{c}\text { Impact of sales commission on } \\
\text { patients' trust in doctors }\end{array}$ & Code $(\mathrm{x})$ & $\mathrm{f}$ & $\mathrm{fx}$ \\
\hline Very Good & -2 & 3 & -6 \\
\hline Good & -1 & 9 & -9 \\
\hline Average & 0 & 5 & 0 \\
\hline Bad & 1 & 26 & 26 \\
\hline Very Bad & 2 & 57 & 114 \\
\hline Total & & 100 & 125 \\
\hline
\end{tabular}

Mean $=1.25$

Mean value is 1.25 which confirms that sales commission as a sales promotion technique negatively influences patients' trust in doctors.

\begin{tabular}{|c|c|c|c|}
\hline $\begin{array}{c}\text { Impact of sales commission on } \\
\text { patients' trust in pharmaceutical } \\
\text { companies }\end{array}$ & Code (x) & $\mathrm{f}$ & $\mathrm{fx}$ \\
\hline Very Good & -2 & 6 & -12 \\
\hline Good & -1 & 8 & -8 \\
\hline Average & 0 & 1 & 0 \\
\hline Bad & 1 & 18 & 18 \\
\hline Very Bad & 2 & 67 & 134 \\
\hline Total & & 100 & 132 \\
\hline
\end{tabular}

Mean $=1.32$

Mean value is 1.32 which discloses that sales commission as a sales promotion technique is not appreciated by patients and it negatively influences their trust in pharmaceutical companies. 


\begin{tabular}{|c|c|c|c|}
\hline $\begin{array}{c}\text { Impact of sponsored trips on } \\
\text { patients' }\end{array}$ & Codest $(\mathrm{x})$ & $\mathrm{f}$ & $\mathrm{fx}$ \\
\hline Very Good & -2 & 15 & -30 \\
\hline Good & -1 & 12 & -12 \\
\hline Average & 0 & 21 & 0 \\
\hline Bad & 1 & 11 & 11 \\
\hline Very Bad & 2 & 41 & 84 \\
\hline Total & & 100 & 53 \\
\hline
\end{tabular}

Mean $=0.53$

Mean value 0.53 reveals that sponsored trips as a sales promotion tool has also a little-bit negative impact on patients' trust in doctors.

\begin{tabular}{|c|c|c|c|}
\hline $\begin{array}{c}\text { Impact of sponsored trips on } \\
\text { patients' trust in pharmaceutical } \\
\text { companies }\end{array}$ & Code (x) & $\mathrm{f}$ & $f x$ \\
\hline Very Good & -2 & 2 & -4 \\
\hline Good & -1 & 19 & -19 \\
\hline Average & 0 & 11 & 0 \\
\hline $\mathrm{Bad}$ & 1 & 31 & 31 \\
\hline Very Bad & 2 & 37 & 74 \\
\hline Total & & 100 & 82 \\
\hline
\end{tabular}

Mean $=0.82$

Sponsored trips as a sales promotion tool negatively affects patients' trust in pharmaceutical companies, mean value reveals the fact.

\begin{tabular}{|c|c|c|c|}
\hline $\begin{array}{c}\text { Impact of sample drugs on } \\
\text { patients' trust in doctors }\end{array}$ & Code $(\mathrm{x})$ & $\mathrm{f}$ & $\mathrm{fx}$ \\
\hline Very Good & -2 & 17 & -34 \\
\hline Good & -1 & 56 & -56 \\
\hline Average & 0 & 10 & 0 \\
\hline Bad & 1 & 13 & 13 \\
\hline Very Bad & 2 & 4 & 8 \\
\hline Total & & 100 & -69 \\
\hline
\end{tabular}

Mean $=-0.69$

Mean value is -0.69 which discloses that sample drugs as a sales promotion tool have a positive impact on patients trust in doctors. 


\begin{tabular}{|c|c|c|c|}
\hline $\begin{array}{c}\text { Impact of sample drugs on } \\
\text { patients' trust in pharmaceutical } \\
\text { companies }\end{array}$ & Code $(\mathrm{x})$ & $\mathrm{f}$ & fx \\
\hline Very Good & -2 & 63 & -126 \\
\hline Good & -1 & 18 & -18 \\
\hline Average & 0 & 0 & 0 \\
\hline $\mathrm{Bad}$ & 1 & 16 & 16 \\
\hline Very Bad & 2 & 3 & 6 \\
\hline Total & & 100 & -122 \\
\hline
\end{tabular}

Mean $=-1.22$

Mean value is -1.22 which shows that sample drugs as a sales promotion technique is being appreciated by the patients. This tool of sales promotion positively contributed towards patients trust in pharmaceutical companies.

\begin{tabular}{|c|c|c|c|}
\hline $\begin{array}{c}\text { Impact of literature on patients' } \\
\text { trust } \text { in doctors }^{\prime}\end{array}$ & Code (x) & $\mathrm{f}$ & $\mathrm{fx}$ \\
\hline Very Good & -2 & 29 & -58 \\
\hline Good & -1 & 44 & -44 \\
\hline Average & 0 & 16 & 0 \\
\hline Bad & 1 & 10 & 10 \\
\hline Very Bad & 2 & 1 & 2 \\
\hline Total & & 100 & -90 \\
\hline
\end{tabular}

Mean $=-0.9$

Literature as sales promotion technique is being appreciated by the patients and mean value reveals that it has a positive impact on patients trust in doctors.

\begin{tabular}{|c|c|c|c|}
\hline $\begin{array}{c}\text { Impact of literature on patients' } \\
\text { trust in pharmaceutical companies }\end{array}$ & Code $(\mathrm{x})$ & $\mathrm{f}$ & $\mathrm{fx}$ \\
\hline Very Good & -2 & 46 & -92 \\
\hline Good & -1 & 12 & -12 \\
\hline Average & 0 & 20 & 0 \\
\hline Bad & 1 & 10 & 10 \\
\hline Very Bad & 2 & 12 & 24 \\
\hline Total & & 100 & -70 \\
\hline
\end{tabular}

Mean $=-0.7$

Mean value -0.7 discloses that literature as a sales promotion tool have a positive impact on patients' trust in pharmaceutical companies. 


\section{Conclusion And Recommendations:}

One thing is quite obvious from data analysis that different sales promotion techniques have different impact on patients' trust. Gifts, sales commission and sponsored trips have a negative impact on patients' trust towards doctors as well as pharmaceutical industry while sample drugs and literature have a positive impact on the trust of patients' towards both the parties. We can say that those promotional techniques which are not just for the sake of doctors and pharmaceutical industry are being appreciated by the patients while those techniques which are totally for the sake of doctors and pharmaceutical industry are not being respected, entire sales promotion cannot be blamed for negative impact on trust but, there are certain techniques which are contributing towards it.

Patient is one of the most important stake holders of health-care industry. From moral point of view entire industry is supposed to serve them as well as much as possible. It is a matter of fact that the members of health care industry e.g. pharmaceutical companies also have financial goals and objectives, in order to survive they must have to achieve those targets but by considering patients perspective in their strategies and by trying to give some benefits of sales promotion techniques to patients as well they can create a very good imagein the minds of patients in Pakistan.

\section{References:}

1. Ahmed, R. R. (2012). Pharmaceutical Drug Promotion in Pakistan: Issues in Ethical and Non-ethical Practices. Interdisciplinary Journal of Contemporary Research in Business, 149.

2. Aisha Muhammad Arif, K. A. (2015). Pharmaceutical Marketing Communication Strategies and Tools; Analysis of influence over physician's prescribing preferences. Scholars Academic Journal of Pharmacy, 4(4):232.

3. Allan S. Brett, M., Wayne Burr, M., \& Jamaluddin Moloo, M. M. (2003). Are Gifts From Pharmaceutical Companies Ethically Problematic? Archives of Internal Medicine, 163:2213.

4. Amin, I. A. (2012). The Impact of Doctor-Pharma Relationships on Prescribing Practice. Journal of Basic and Applied Sciences, 8:174.

5. Avinash R. Patwardhan, M. (2016). Physicians-Pharmaceutical Sales Representatives Interactions and Conflict of Interest: Challenges and Solutions. The Journal of Health Care Organization, Provision, and Financing, 53:1.

6. Howard Brody, M. P. (2005). The Company We Keep: Why Physicians Should Refuse to See Pharmaceutical Representatives. Annals of Family Medicine, 3(1):82. 
7. Hsiao, W. C. (2008). When Incentives And Professionalism Collide. HEALTH AFFAIRS, 27(4):950.

8. Jason Dana, M., \& George Loewenstein, P. (2003). A Social Science Perspective on Gifts to Physicians from Industry. The Journal of the American Medical Association, 252.

9. Kenneth V. Iserson, M. M. (2007). Politely Refuse the Pen and Note Pad: Gifts From Industry to Physicians Harm Patients. The Annals of Thoracic Surgery, 84:1078.

10. Kerridge, P. A. (2002). Ethical issues concerning the relationships between medical practitioners and the pharmaceutical industry. Clinical Ethics, 176:119.

11. Macneill P, K. I. (2010). Attitudes of physicians and public to pharmaceutical. Internal Medicine Journal, 40:1.

12. Mehmood, Y. (2016). Challenges Fasces by MNCs in Pakistan Due To Unethical Practice of National Pharmaceuticals. Journal of Hospital and Clinical Pharmacy, 24,25.

13. Narendranathan, R. N. (2013). Influence of pharmaceutical marketing on prescription practices of physcians. The Journal of the Indian Medical Association, 111(1):3,4.

14. Rhee, J. (2008). The Influence of the Pharmaceutical Industry on Healthcare Practitioners' Prescribing Habits. The Internet Journal of Academic Physician Assistants, 7(1):4.

15. Rizwan Raheem Ahmed, I. K. (2014). Marketing Practices of Pakistan Pharmaceutical Industry and Physician Prescription Behavior. World Applied Sciences Journal, 3(5):910-912.

16. Robert L. Blake, J. M. (1995). Patients' Attitudes About Gifts To Physicians From Pharmaceutical Companies. The Journal of the American Board of Family Practice, 8:1.

17. Robert V. Gibbons, M. M. (1998). A Comparison of Physicians' and Patients' Attitudes. Journal of General Internal Medicine, 13:1.

18. Shahzad Salmasi, L. C. (2016). Interaction and medical inducement between pharmaceutical representatives and physicians: a metasynthesis. Journal of Pharmaceutical Policy and Practice, 9:2.

19. Zaman, M. A. (2011). Review of Pakistan Pharmaceutical Industry: SWOT Analysis. International Journal of Business and Information Technology, 1(1):114. 
APPENDIX:

QUESTIONNAIRE

Dear Respondent, the purpose of this questionnaire is to identify the patients' point of view about different sales promotion techniques used by pharmaceutical companies. It is for academic purpose.

Name:

Age:

Gender:

1- The impact of gifts given to doctors by pharmaceutical companies on your trust indoctors is
(a) Very Good
(b) Good
(c) Average
(d) Bad
(e) Very Bad

2- The impact of gifts given to doctors by pharmaceutical companies on your trust in pharmaceutical companies is
(a) Very Good
(b) Good
(c) Average
(d) Bad
(e) Very Bad

3- The impact of sales commission given to doctors by pharmaceutical companies on your trust in doctors is
(a) Very Good
(b) Good
(c) Average
(d) Bad
(e) Very Bad

4- The impact of sales commission given to doctors by pharmaceutical companies on your trust in pharmaceutical companies is
(a) Very Good
(b) Good
(c) Average
(d) Bad
(e) Very Bad 
5- The impact of trips for doctors sponsored by pharmaceutical companies on your trust in doctors is
(a) Very Good
(b) Good
(c) Average
(d) Bad
(e) Very Bad

6- The impact of trips for doctors sponsored by pharmaceutical companies on your trust in pharmaceutical companies is
(a) Very Good
(b) Good
(c) Average
(d) $\mathrm{Bad}$
(e) Very Bad

7- The impact of sample drugs given to doctors by pharmaceutical companies on your trust in doctors is
(a) Very Good
(b) Good
(c) Average
(d) Bad
(e) Very Bad

8- The impact of sample drugs given to doctors by pharmaceutical companies on your trust in pharmaceutical companies is
(a) Very Good
(b) Good
(c) Average
(d) Bad
(e) Very Bad

9- The impact of literature (posters, charts, pamphlets for general public awareness) given to doctors by pharmaceutical companies on your trust in doctors is
(a) Very Good
(b) Good
(c) Average
(d) Bad
(e) Very Bad 
10- The impact of literature (posters, charts, pamphlets for general public awareness) given to doctors by pharmaceutical companies on your trust in pharmaceutical companies is
(a) Very Good
(b) Good
(c) Average
(d) Bad
(e) Very Bad 